\title{
The Impact of Information Communication Technology (ICT) on Procurement Processes: Case of Zimbabwean Urban Councils (2009 to 2018)
}

\author{
Shakespear Mabhodha \\ Chinhoyi University of Technology, Chinhoyi, ZIMBABWE \\ Farai Choga \\ Zimbabwe Open University, Harare, ZIMBABWE \\ Faculty of Commerce and Law
}

Received: 9 July 2021 • Accepted: 19 September 2021 • Published Online: 11 October 2021

\begin{abstract}
The research aimed at determining the impact of ICT applications on procurement processes. The population of study was composed of 110 respondents from Chegutu, Kadoma, Kwekwe, Chinhoyi and Gweru urban councils with a representative sample of eighty-six participants all drawn from the procurement, finance and works departments of the five councils. Quota sampling was used in this research with strata based on the level of employment in the three different divisions. The research utilized a proportion of $78 \%$ from each stratum to select eightsix respondents. Both primary and secondary data was used. Primary data was collected through questionnaire which was designed to satisfy research objectives. Secondary data came from relevant literature review, journals, business magazines, conference papers, and internet. Questionnaire responses were tabulated, coded by use of Statistical Package for Social Sciences (SPSS) version 16 to analyze quantitative data. Qualitative analysis was used to obtain in depth knowledge of the level of ICT utilization and why users were operating at different levels. Findings of the study indicated that although ICT infrastructure with procurement application is in existence and available, utilization of Information Communication Technology is at basic level. Acceptance and adoption of ICT in procurement was driven by both organization and personal objectives. The view that technology adoption is based on the Technology Acceptance Model was applied in this study by testing the perceptions of ease of use and usefulness of ICT. The study revealed that ICT adoption in procurement improves the process and benefits other operations of the business. ICT training and skills development, coupled to organizations' leadership commitment and availability of financial resources were cited as critical success factors in the acceptance and improved utilization of ICT in procurement. The researchers recommended further studies on the topic of ICT adoption in business operations by public entities.
\end{abstract}

Keywords: Information Communication Technology, e-procurement, council.

\section{Background of the study}

(C) Authors. Terms and conditions of Creative Commons Attribution 4.0 International (CC BY 4.0) apply. Correspondence: Farai Choga, Zimbabwe Open University, Faculty of Commerce and Law, Harare, ZIMBABWE. E-mail: chogaf@zou.ac.zw. 
Local government authorities have been slow to adopt electronic procurement systems despite the existence of basic information communication infrastructure. This is probably because of some resistance to change by being blinkered to papers and files (Chimberengwa et al., 2015).

Sixty percent of the government's expenditure in Zimbabwe is allocated to public procurement which is very high when considering the liquidity challenges accompanied by a balance of payments deficit (Mushanyuri, 2014). This is the main reason why the public has placed much blame on public procurement as a result of its failure to provide public services and utilities (Chigudu, 2014). Poor service delivery in Zimbabwe is indicated by shortages of medicinal requirements and poor quality of procured goods and these problems are emanating from poor planning, poor execution of contracts and the major one being unavailability of adequate technologies in public procurement (Chimberengwa et al., 2015). With the adoption of ICT, procurement processes can be approved online and the order fulfilled within minutes where the required item often arrives in real time (Chigudu, 2014). Main Information Communication Technological systems currently used in public procurement contracts are the Systems Application Programmes (SAP) and websites of which are not fully adopted as some local authorities even do not completely use it (Chimberengwa et al., 2015). The websites should be used by local government authorities to invite suppliers to bid and call for submission of quotations (Musanzikwa, 2013). Templates for bidding documents as well as the contract formation templates are all available on the Procurement Regulatory Authority of Zimbabwe (PRAZ) website. The platform is being used by the PRAZ to communicate mainly with its stakeholders being public entities and suppliers of different categories of goods and services.

It is against this background that this research aimed to find out the effect of information communication technology on effective procurement management in local authorities.

\section{Statement of the problem}

Councils are yet to fully adopt and utilize the benefits of employing high level information communication technological tools such as online supplier registration and eprocurement. The impact of these tools on the procurement process is not yet known.

\section{Research objective}

The objective of this research was to determine the impact of ICT applications and infrastructure that affect councils' procurement processes.

\section{Literature review}

\subsection{Theoretical framework}

Theoretical framework used in this study was the technology acceptance model (TAM) by Davis (1996). This model supports the concept that perception of users influences the degree and level to which technology is used in business and other organizations. According to this theory, emerging technologies cannot improve organizational effectiveness and performance if the change has not been accepted by the technology users. The theory of technology acceptance is one of the most popular theories in understanding adoption of computer technologies. It avers that adoption of any innovation requires investment in computer-based tools to support decision making, planning and communication (Kamel, 2014). Before accepting any technology, users should be aware of the benefits and security and other risky issues involved. 
This theory is important in this research as it provides the factors that influence people to accept technology. The study of the impact of technology on procurement process revolves around this theory because the research is about exploring the extent to which ICT is utilized by individuals employed in municipalities.

\subsection{Impact of ICT on procurement processes}

Varma and Khan (2014) in their study of Information Technology in Supply Chain concluded that many scholars have advocated for paperless transaction in procurement by adopting the use of System Applications and Products (SAP) in Data Processing by using Enterprise Resource Planning (ERP) systems, Automatic Identification and Electronic Data Interchange modules. These systems guarantee transparency and security of the systems to both the user and the businesses. From the research conducted by Nair (2012) titled RFID for supply chain management, the findings were that the respondents thought that procurement based on ICT tools easily controls and manages information interchange within key business functions, products, external and internal financial resources and contributes to business profitability by enhancing quality and alleviating coordination costs and trading risks.

Numerous analysts have debated on the role between ICT tools in procurement among them Nair (2013) published a study titled E-Supply chain management using software agents. Their findings had a common agreement that ICT enhances information sharing, improves the performance and eradicates supply chain risks by providing system and procedure-based execution of tasks and presents information to decision makers in formats that it's needed. Moon (2007) conducted research on Enterprise Resource Planning (ERP) and concluded that ICT played critical role in the integration of suppliers and customers to ensure the right quantity and quality of products are supplied. Auramo et al. (2005) in their exploration of Benefits of IT in Supply Chain Management to Finnish Companies found out that ICT was being applied to data entry, real time processing, and regularization of transaction that were expected to create a balance between supply and demand among procurement chain members. Brooks and Davenport in their 2004 study of Enterprise systems and the supply chain concluded that ICT was as a critical requirement for managing and control of procurement processes.

Bertschek, Cerquera and Klein (2013) measured the impact of broadband internet on firm performance asserted that the internet had become the major source of information, products and services and e-procurement has become one of the most discussed topics in supply chain management and will revamp the mechanics and methods of purchasing in the coming years. Craig, Carter and Washispack (2018) noted that both developed and developing nations have adopted ICT to improve public service delivery, enhance the general populace's access to information and increase civil society participation in economic and political affairs. Chebii (2016) studied the Kenya situation and concluded that most nations have realized public involvement in government bidding processes and were on a trajectory that creates opportunities for all suppliers to improve public service delivery.

Ambe (2016) studied public procurement trends and developments in South Africa acknowledged that e-procurement adopted by most nations in the world economy as a means to lessen the burden of obtaining information. Cheptora (2018) studied the impact of ICT on procurement performance in manufacturing firms in Kenya and found out that the e-procurement system is comprised of indent management, e-tendering, electronic auctioning, vendor management, catalogue management and contract management and further defined indent management as the software package that involves tender or bids preparations. Brooks (2004) in research that explored enterprise systems and the supply chain, observed that indent management permits online purchase requisitions, ordering, and tracking of ordered products and management of stocks. 
Waigwa and Njeru (2016), in their study on the factors influencing management of procurement contracts in public security agencies, concluded that public sector entities utilize eprocurement to obtain gains such enhanced efficiency and cost savings, shorter procurement cycles and enhanced accountability to reduce corruption in procurement by avoiding face to face dealing with service providers. Adebanjo, Tickle, Lin and Bourlakis (2016), on e-business capabilities in developed and developing countries, posited that the public sector had widely accepted e-procurement and its utilization graph has grown exponentially. According to Chimberengwa et al. (2015), in the research on procurement processes at Gwanda Provincial Hospital, Matabeleland South Province Zimbabwe stated that Zimbabwean public sector is still to fully embrace e-procurement. Chigudu (2014) conducted research on public procurement in Zimbabwe and concluded that the rewards that entities benefit from the acceptance and utilization of e-procurement networks and systems are enormous. Local authorities in Zimbabwe must establish ICT frameworks for improved service delivery noted Dzuke and Naude (2017) in their study on the problems affecting operational procurement process in Zimbabwe.

However, beyond the use of emails and adoption of mobile payments by urban councils, the applications adopted for procurement by local authorities in Zimbabwe are not known. The levels to which ICT applications are utilized in procurement by local authorities need further research. The impact of these applications in procurement process of local council is relatively unknown and therefore this warrants further research.

\section{Research methodology}

This study utilizes the pragmatist research philosophy that provides the researcher with the freedom of choosing the research methods and techniques that best satisfy the needs and objectives of the research. A deductive approach was used. The targeted population of 110 respondents was drawn from Chegutu, Kadoma, Kwekwe, Chinhoyi and Gweru municipalities. Selected individuals were drawn from the Procurement Management Unity and the Department of Works and Treasury Department since these are the departments which are directly responsible for the implementation of procurement and contract management within the councils.

The population was divided into strata according to their work department; procurement, finance and works as they exist in urban councils which are mutually exclusive. These departmental strata were further subdivided according to job titles and sample size was determined using the mathematical formula $\mathrm{n}=\mathrm{N} / 1+\left(\mathrm{N} *(\mathrm{e}){ }^{2}\right)$ at $95 \%$ level of confidence to determine the representative proportion of each sub-stratum as shown below.

Table 1. Sample size

\begin{tabular}{|l|l|l|l|l|}
\hline \multicolumn{5}{|c|}{ Sample Size } \\
\hline Quotas & N & n/N & $\mathbf{n}^{\mathbf{1}}$ & $\mathbf{n}^{\mathbf{2}}$ \\
\hline Procurement Department & & & & \\
\hline Town Clerk & 5 & $78 \%$ & 3.91 & 4 \\
\hline Procurement Managers & 5 & $78 \%$ & 3.90 & 4 \\
\hline Procurement Officers & 10 & $78 \%$ & 7.80 & 8 \\
\hline Support Staff & 20 & $78 \%$ & 15.60 & 16 \\
\hline Procurement Population & $\mathbf{4 0}$ & $78 \%$ & 31.20 & $\mathbf{3 2}$ \\
\hline & & & & \\
\hline Treasury Department & & & & \\
\hline Finance Directors & 5 & $78 \%$ & 3.90 & 4 \\
\hline
\end{tabular}




\begin{tabular}{|c|c|c|c|c|}
\hline Finance Manager & 5 & $78 \%$ & 3.90 & 4 \\
\hline Accounts Support Staff & 20 & $78 \%$ & 15.60 & 15 \\
\hline Treasury Population & 30 & $78 \%$ & 23.40 & 23 \\
\hline \multicolumn{5}{|l|}{ Works Department } \\
\hline Director of Works & 5 & $78 \%$ & 3.90 & 4 \\
\hline Project Engineers & 15 & $78 \%$ & 11.70 & 12 \\
\hline Technicians & 20 & $78 \%$ & 15.60 & 15 \\
\hline \multirow[t]{2}{*}{ Works Population } & 40 & $78 \%$ & 31.20 & $\mathbf{3 1}$ \\
\hline & 110 & & & 86 \\
\hline \multicolumn{5}{|l|}{ Legend } \\
\hline \multicolumn{5}{|l|}{$\mathbf{N}$-population Size } \\
\hline \multicolumn{5}{|c|}{$\mathbf{n} / \mathbf{N}$ : sample size ratio to Population } \\
\hline \multicolumn{5}{|l|}{$\mathbf{n}^{\mathbf{1}}$ : calculated sample size } \\
\hline $\mathbf{n}^{2}:$ actual sample size & & & & \\
\hline
\end{tabular}

The sample size has a total number of 86 respondents.

\section{Results and discussion}

The response rate was $84 \%$.

\subsection{ICT level of usage}

The respondents acknowledged that ICT application in procurement promote accountability, transparency and integrity not only in procurement but in all organization functions. The above observations echoed Varma and Khan (2014) who advocated for paperless transaction in procurement by adopting System Applications and Products (SAP) in data processing by using Enterprise Resource Planning (ERP) systems, Automatic Identification and Electronic Data Interchange modules. These systems guaranteed transparency and security of the systems to both the user and the business.

The research revealed that use of ICT tools in procurement was at a very basic level although it was encouraging to note that most users acknowledged the benefits of using ICT tools, which means initiatives to push for the full adoption of e-procurement, would face less challenges. The respondents further added that most of the procurement tasks were being performed using manual work from generating purchase requisitions to issuing purchase orders and creating and generating tender documents and request for quotations creating challenges in keeping record secure and safe because of the volume of space needed. The tendering process was done manually from tender compilation, submission, evaluation and awarding and contract signing. This was also noted by Dzuke and Naude (2017), who observed that in Zimbabwe public procurement was underpinned by hardcopies in the tendering process. Further investigations showed hundred percent of the respondents use Google mail hosted personal email to communicate business issues with stakeholders. Requests for quotations and bid documents were sent to suppliers using emails and sometimes prospective bidders are notified to collect hard copies. Microsoft tools were being used in basic operations such as writing letters, creating Request for Quotations, tender 
documents and general communications and simple Excel tools. This was supported by one of the participants, who mentioned that,

"We make use of many Information Communication Technology packages with respect to one's position and literacy to a specific package. But however, we mostly use Sage in our organization...”

SAP as an ICT Application being used was scored high. Hence implying that SAP Application was highly used in the organization's participants. However, the use of Microsoft tools was ranked low this was due to the issues of Data Security and Data Management as they have minimum analysis tools hence making them less competitive and of minimum use. One of the participants mentioned that,

"Sage systems are highly used for order processing and creditors control and also

Microsoft packages for simple use in the writing of letters..."

\subsection{ICT Application in tendering process}

The majority of the respondents indicated that they agreed with the level on which the ICT packages were being used to perform the tendering tasks. The findings concur with Lysons and Farrangton (2012). The significance of these results is that the application of ICT in procurement contracts appeared to have not gained the required momentum.

This observation is in tandem with Chimberengwa et al. (2015), who noted that the Zimbabwean public sector is still to fully embrace e-procurement. Chigudu, 2014 concluded that the rewards that entities benefit from the acceptance and utilization of e-procurement networks and systems are enormous. Local authorities in Zimbabwe must establish ICT frameworks for improved service delivery noted Dzuke and Naude (2017) in their study on the problems affecting operational procurement process in Zimbabwe.

\subsection{ICT Applications in purchasing task}

The findings indicated that the respondents agreed with the views that the rate adoption of technology in public procurement is very slow as concluded by Chigudu (2014) and Dzuke and Naude (2017), who agreed that public procurement is characterized by a lot of hard copy paper work and further recommended that ICT adoption in procurement must be anchored on national policy.

\subsection{Challenges faced in adopting ICT in procurement}

High cost of introducing new ICT systems, lack of consultancy expertise in Eprocurement, lack of leadership were the challenges that were ranked high. Slow rate of suppliers linking with system, difficult in measuring usefulness and potential of ICT and difficult in measuring ease of use were some of the cited challenges.

Further inquiry into the challenges brought the issues of resistance mainly from employees who perceive the introduction of technology take away their jobs. Most of the employees from forty-six years old and above preferred the status quo of paper files and hard copy paper pressing. Although most respondents acknowledged that ICT improves the procurement process, the researchers gathered from discussions that most users lacked the will and personal intent to utilize ICT. The participants blamed slow adoption and lack of capital investments on poor leadership, management's lack of foresight and unwillingness to adapt to dynamic business operations driven by technological automation as one respondent put it: 
"Management uses lack of funds as an excuse not to invest in ICT because they know once ICT is adopted in procurement their corrupt activities will be known".

This reflected that personal attitude and commitment of organizational leadership has a direct impact on the adoption of technology in municipalities. As reported by the World Bank (2013), organization leadership has the obligation of establishing the vision and mission of the firm, motivating their teams for change in process and organizational culture, and establishing the policies and strategies necessary to put an e-Procurement initiative in place If the e-procurement system does not have the full support of the top management team, there is every reason for it to fail The interviews and discussions that were held with respondents pinpoint the fact that as much as financial resources are scarce the major issue that prohibited the adoption of ICT in procurement is the attitude of executive management that lacks the tenacity and ability to raise funding for investments into ICT to adapt to the dynamic and ever changing demands of the people they serve.

\subsection{Solutions to challenges in ICT adoption in procurement}

From the study findings, the respondents indicated that early supplier involvement and capability development efficiency supply chain risk management, encourage user acceptance and readiness, employee training, capital investment on technology and senior management commitment were the possible solutions that underpinned this study.

The respondents appreciated that lack of capital investment was a challenge but they advocated for leadership change in municipalities blaming it for the slow adoption of technology in councils' operations and particularly in procurement. The respondents explain the basis of their ratings and they indicated that it was imperative for the municipalities to consider the acceptance of the technology by important stake holders such as suppliers and rate payers. They further indicated that it was necessary to adopt technology in procurement to create transparency and accountability but a balance has to be found between investing in technology or utilizing funds for the improvement of service delivery to rate payers. From the interviews most were of the opinion that for ICT to be adopted in procurement must be driven by the national government through the relevant ministry be considered a national policy that mandates municipalities to fully utilize ICT in procurement and promotes accountability and transparency as envisaged by the Public Procurement and Disposal of Public Assets Act Chapter 22:23 and the Zimbabwe National Policy for Information communication technology.

\section{New conceptual framework}

The figure below indicates the impact of organizational leadership as a primary independent variable that influences the secondary variables that impact on ICT usage levels in the procurement process.

The study thus recommends that the organizations should be sensitive of the changing business environment that dictates the competitive environment they operate in. As such, staying ahead of the competition through adoption of ICT would ensure that the organizations survive in the competitive environment. Embracing of Information Communication Technology (ICT) ensures that the supply chain balances its need to satisfy customer needs and manage costs in order to attain profits. 


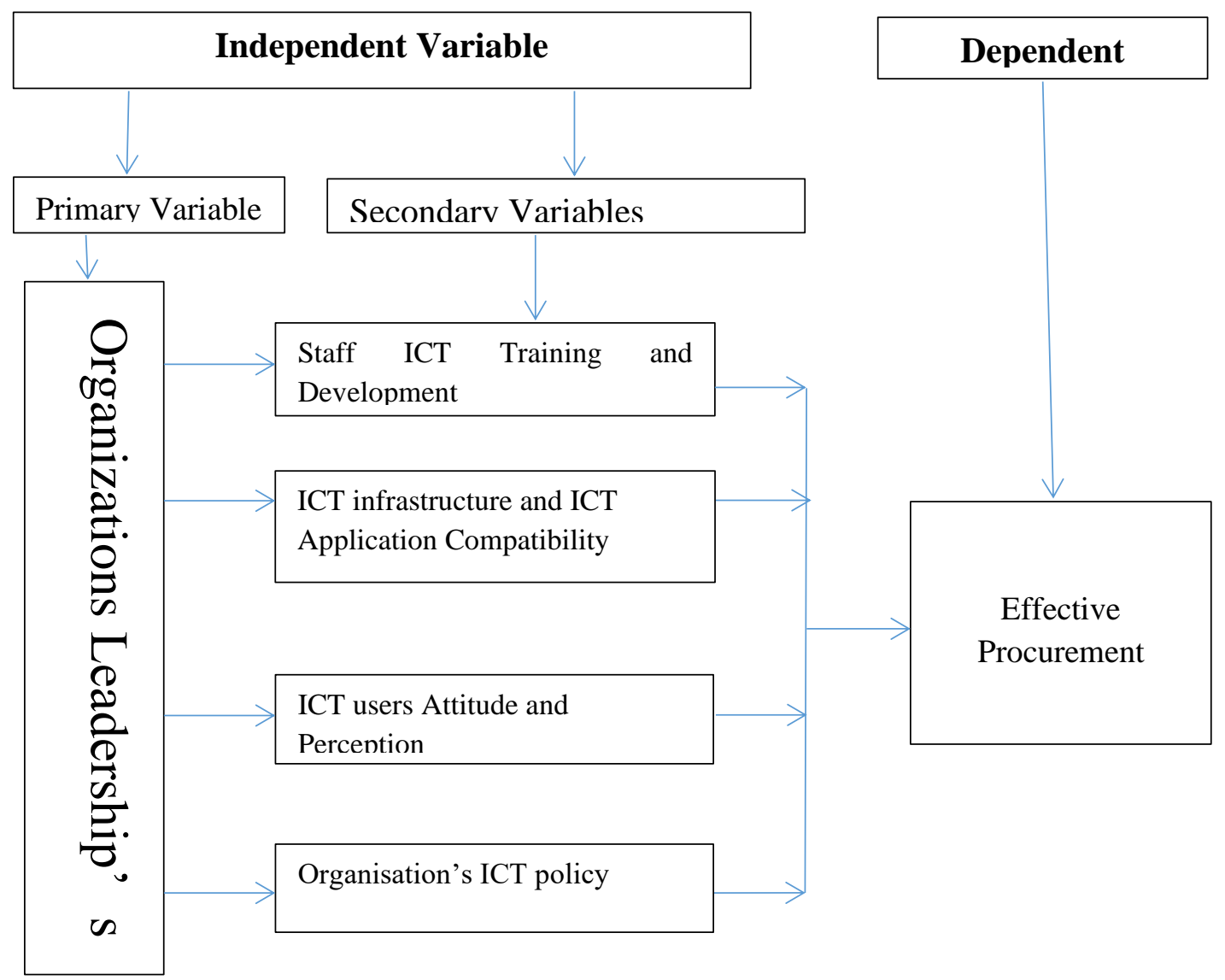

Figure 1. New conceptual framework researched on.

This conceptual framework was generated from above findings and still needs to be

\section{Conclusion}

On the issue of ICT skills, most respondents do not have formal ICT training except very basic ICT contributing to the slow rate of ICT adoption. The municipalities have basic ICT infrastructures and make use of computers and internet albeit at a very basic level, that is communication and supplier search on the internet. Most of the procurement tasks are still paper based. The tendering processes used to procure goods through the public procurement system is still very much paper based, with some municipalities refusing to accept bids submitted on emails preferring hard copy papers. The existing ICT infrastructure in municipalities is almost approaching the end of its life cycle creating challenges of compatibility and dynamic adaption of new technologies in procurement. The councils lack financial resources to invest in current innovative technologies in procurement. Although the national government has initiated the national policy on ICT, the municipalities lag behind in adoption.

On the impact of personal attitude and organization policy on the adoption of ICT in procurement it is concluded that most users adopt technology based on their perception of its usefulness and ease of use. However organizational policy enforces employees to utilize the technology since some tasks require the use of technology irrespective of the employees' perception. The leadership in the organizations have no commitment to ICT adoption as revealed by most respondents. The municipalities lack innovative leadership to adapt and survive in this economy and improve service delivery. 


\section{Recommendations}

From the conclusions above it is therefore recommended that organizations must equip their employees with the necessary skills through training and skills development in ICT. Recruitment policy must emphasize that employees must be ICT skilled and innovative. Further the municipalities must improve the ICT infrastructure in order for it to be compatible with new software applications. Further it must be made mandatory that procurement tasks be performed through ICT and that ICT task implementation be given first priority.

Executive management must take a leading role in advocating for ICT in procurement and all other functions of the organization. Established procedures and regulations must acknowledge and appreciate the perception of users and recognize that users' perception also plays an important role in the adoption and ICT and usage level in procurement.

\section{Acknowledgements}

This research did not receive any specific grant from funding agencies in the public commercial, or not-for-profit sectors.

The authors declare no competing interests.

\section{References}

Adebanjo, D., Tickle, M., Lin, Y., \& Bourlakis, M. (2016). E-business capabilities in developed and developing countries: Different or the same? In Management of Innovation and Technology (ICMIT), 2016 IEEE International Conference on IEEE (pp. 19-24).

Ambe, M. I. (2016). Public procurement trends and developments in South Africa. Research Journal of Business and Management-(RJBM), 3(4).

Auramo, J., Kauremaa, J., \& Tanskanen, K. (2005). Benefits of IT in Supply Chain Management- an Explorative study of progressive Finnish Companies. International Journal of Physical Distribution and Logistics Management, 35(2).

Bertschek, I., Cerquera, D., \& Klein, G. J. (2013). More bits- more bucks? Measuring the impact of broadband internet on firm performance. Information Economics and Policy, 25, 190-203.

Brooks, F. D. (2004). Enterprise systems and the supply chain. Journal of Enterprise Information Management, 17(1), 8-19.

Cheptora, N. C. (2018). The impact of information and communication technology on procurement performance in manufacturing firms in Kenya. International Journal of Academic Research in Business and Social Sciences, 8(9), 605-616.

Chigudu, P. (2014). Public procurement in Zimbabwe: Issues and challenges. Journal of Governance and Regulation, 3(4), 21-26.

Chimberengwa, P. T. (2015). Procurement processes at Gwanda Provincial Hospital, Matebeleland South Province Zimbabwe. Audit Journal of Public Health and Epidemiology, 2, 1018.

Craig, R., Carter, C. R., \& Washispack, S. (2018). Mapping the path forward for sustainable supply chain management: A review of reviews. Journal of Business Logistics, 39(4).

Davis, F. D. (2011). State of the manufacturing sector: CZI Report, Harare. Perceived usefulness, ease of use and user acceptance of information technology. Harare: Confederation of Zimbabwe Industries Report. 
Dzuke, A., \& Naude, J. A. (2017). Problems affecting operational procurement process: A study of Zimbabwean public sector. Journal of Transport and Supply Chain Management, 11, 255.

Kamel, S. (2014). The use of information technology to transform the banking sector in developing nations. Information Technology for Development, 11(4), 305-312.

Lysons, K., \& Farrington, B. (2012). Purchasing and supply chain management. Essex: Pearson Education.

Musanzikwa, M. (2013). Public procurement system challenges in developing countries: The case of Zimbabwe. International Journal of Economics, Finance and Management Sciences, 1(2), 119-127.

Mushanyuri, B. (2014, September 19). Features opinions and analysis-call for procurement system review. Retrieved 30 March 2020, from The Herald: http://www.herald.co.zw.

Nair, P. R. (2012). RFID for supply chain management. CSI Communications, 36(8), 14-18.

Varma, T. N. (2014). Information technology in supply chain management. Journal of Supply Chain Management.

Waigwa, M. W., \& Njeru, A. (2016). Factors influencing management of procurement contracts in public security agencies: A case of Kenya Police Service. International Academic Journal of Procurement and Supply Chain Management, 2(2), 20-40. 